\title{
INHERITANCE OF DIAPAUSE INDUCTION AND INTENSITY IN PAPILIO ZELICAON
}

\author{
STEVEN R. SIMS \\ AREC Univ. of Florida 18905 S.W. 280th St. Homestead, FI. 33031, U.S.A.
}

Received 15.iv.83

\section{SUMMARY}

Five generations of mass selection reduced "obligate" diapause, critical photoperiod, and diapause intensity in a strain of the anise swallowtail, Papilio zelicaon Lucas. Reciprocal crosses made between the selected line and unselected uniand multivoltine populations produced hybrids with diapause induction and intensity intermediate to parental values. The results suggest polygenic inheritance of induction and intensity. Differences in response between reciprocal hybrids indicate the presence of maternal effects on diapause induction. It is proposed that the genetic variance underlying the diapause trait and the switch to non-native host plants have facilitated the evolution of multivoltinism in $P$. zelicaon.

\section{INTRODUCTION}

The anise swallowtail, Papilio zelicaon Lucas, exhibits a pupal diapause which is primarily under photoperiod and temperature control (Sims, 1980). In central California, univoltine populations (with one annual generation) differ from multivoltine populations in having a longer critical photoperiod ( $\mathrm{CP}=$ photoperiod inducing 50 per cent diapause), and a higher incidence of both "obligate" (under long-day warm conditions) and prolonged ( $\geqq 2$ years) diapause (Sims, 1980, 1983).

Recurrent selection of non-diapausing individuals from a multivoltine population-derived lab strain decreased both CP and diapause intensity, that is, the duration of chilling necessary to terminate diapause (Sims, 1980). Response to selection indicates the presence of additive genetic variation for these diapause traits and suggests that some genetic factors influence both. This report details the results of selection for non-diapause and describes the inheritance of diapause induction and intensity observed in pupae from reciprocal crosses made between the selected line (S), and univoltine $(\mathrm{U})$ and multivoltine $(\mathrm{M})$ populations.

Knowledge of the inheritance of diapause induction and intensity in $P$. zelicaon is useful in the following ways; (1) it increases our overall understanding of the diapause process (Hoy, 1978; Tauber and Tauber, 1981), and (2) it allows inferences to be made concerning the apparent recent evolution of multivoltine populations from univoltine ancestors in California following a switch to non-native host plants (Coolidge, 1910; Emmel and Shields, 1978(79); and Horton, 1922).

\section{MATERIALS AND METHODS}

$P$. zelicaon were obtained from two multivoltine California populations; Suisun Marsh, Solano Co., elevation $<10 \mathrm{~m}$, and Rancho Cordova, 
Sacramento Co., el. $<30 \mathrm{~m}$, and 3 univoltine populations, Butts Canyon, Napa Co., el. 500 m, Foresthill, Placer Co., el. 750 m, and Donner Pass, Placer Co., el. $2100 \mathrm{~m}$.

A laboratory culture was initiated using three females from Suisun Marsh and one from Rancho Cordova. These females and females of subsequent generations were maintained under a long day photoperiod (LD14:10 =14 hr light, $10 \mathrm{hr}$ dark) at $23.5^{\circ} \mathrm{C}$, and allowed to oviposit on Foeniculum vulgare Mill. within 2 litre cardboard containers. The resulting eggs were randomised and larvae reared at LD $18: 6,29^{\circ} \mathrm{C}$ on $F$. vulgare in large wood-frame $(46 \mathrm{~cm}$ side) cages. Pupae unemerged after 30 days under the rearing conditions were judged to be in diapause; non-diapause emergence occurred in $10-20$ days at $23 \cdot 5^{\circ} \mathrm{C}$, and $6-10$ days at $29 \cdot 5^{\circ} \mathrm{C}$.

Matings were obtained by hand-pairing non-diapause individuals (Clarke and Sheppard, 1956). Five generations of mass selection were conducted using 7-15 mated females per generation. The incidence of pupal diapause under long days was recorded for each generation. Randomly selected samples of ova from the $F_{1}, F_{3}$, and $F_{5}$ generations were used to test diapause response to short days at $\mathrm{LD} 12: 12,23 \cdot 5^{\circ} \mathrm{C}$.

The genetics of pupal diapause induction was studied by examining the diapause response of hybrids from reciprocal crosses between the selected $(\mathrm{S})$ line $\left(\mathrm{F}_{4}\right.$ and $\left.\mathrm{F}_{5}\right)$ and the univoltine $(\mathrm{U})$ and multivoltine $(\mathrm{M})$ populations under long days, $\mathrm{LD} 14: 10,23 \cdot 5^{\circ} \mathrm{C}$. The $\mathrm{M} \times \mathrm{S}$ and $\mathrm{S} \times \mathrm{M}$ crosses were made using $S$ individuals which had entered diapause under diapauseaverting rearing conditions (LD18:6) in the $F_{1}$ and $F_{2}$ generations (M parents) and non-diapause $\mathrm{F}_{4}$ and $\mathrm{F}_{5}$ individuals ( $S$ parents).

Virgin $U$ females and $S$ females and males were lab-reared the year prior to the crosses and emerged following either extended cold treatment at $11^{\circ} \mathrm{C}$ or overwintering outdoors in Davis, Yolo Co., Ca. (Sims, 1980). The per cent diapause in each cross was arcsine transformed (FreemanTukey transformation for $n \leqq 50$; Mosteller and Youtz, 1961) and analysed using ANOVA procedures and Duncan's Multiple Range test for the significance of differences among means (Sokal and Rohlf, 1969).

The genetics of diapause intensity was studied using samples of pupae from the $U$ and $S$ lines and their reciprocal hybrids. Pupal diapause was induced by rearing at LD12:12, $23 \cdot 5^{\circ} \mathrm{C}$. After five months of maintenance under the rearing conditions, the diapause pupae from each line and cross were divided into two lots and exposed to conditions promoting diapause termination. One lot was kept at LDO : $24,11^{\circ} \mathrm{C}$ for 126 days then returned to $\mathrm{LD} 14: 10,23 \cdot 5^{\circ} \mathrm{C}$ and observed daily for emergence. The other lot was placed in an outdoor cage in Davis, Ca. during October 1976 and 1977 and monitored three times a week the following spring and summer for emergence.

\section{REsults AND Discussion}

The results of selection for non-diapause are shown in fig. 1. From the $\mathrm{F}_{1}-\mathrm{F}_{5}$ generation, non-diapause increased from 79 per cent to 97 per cent under long days and 7 per cent to 18 per cent under short days. Comparison of the $F_{1}$ and $F_{5}$ generations under a range of photoperiods at $23 \cdot 5^{\circ} \mathrm{C}$ showed that selection decreased the $\mathrm{CP}$ by $0.5 \mathrm{hr}$ light $(13.5 \mathrm{hr} \mathrm{L}$ to 


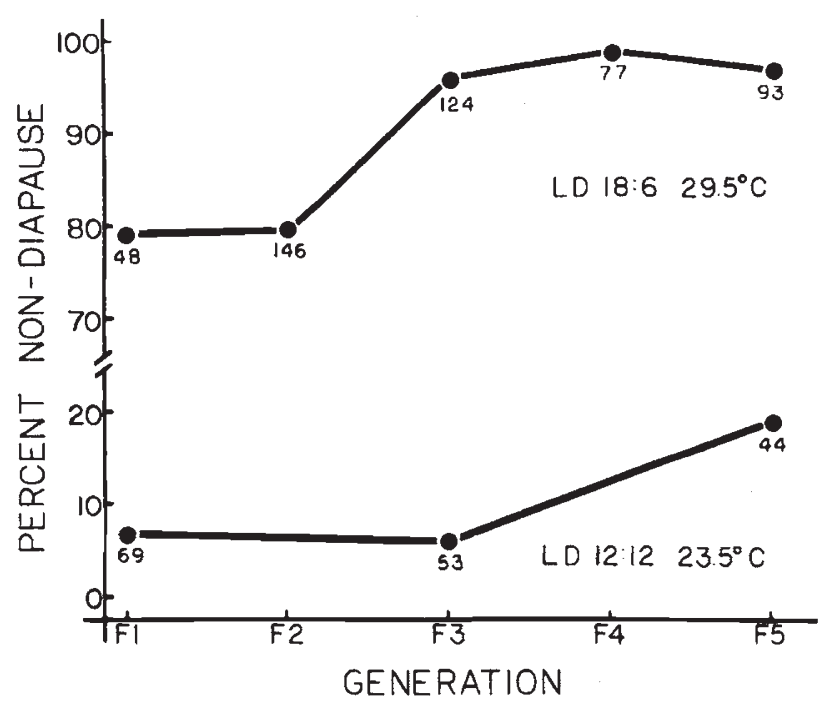

Fig. 1. Change in diapause response to photoperiod of $\boldsymbol{P}$. zelicaon through mass selection at LD18:6, $29 \cdot 5^{\circ} \mathrm{C}$. Numbers indicate sample size.

13.0 hr L) (Sims, 1980). Selection against apparent "obligate" diapause can thus simultaneously modify population photoresponse.

Ancestral populations of California $P$. zelicaon, limited by ephemeral native hosts at low elevations and by a short growing season in the mountains as well, are generally single-brooded. Multivoltine lowland populations occur primarily on sweet fennel ( $F$. vulgare) and Citrus (Emmel and Shields, 1978(79); Sims, 1980). These plants were introduced by the Spaniards during the 18th and mid-19th Century, respectively and share attractive essential oils similar to native Umbellifers (Dethier, 1941). The evolution of multivoltinism in $P$. zelicaon populations probably involved at least two separate phenomena. First, females "switched" their oviposition preference from native to introduced hosts or, through dispersal, found themselves in areas where only introduced hosts were available (Shapiro and Masuda, 1980). Second, use of host-plants which are seasonally available 8-12 months of the year favored continuous reproducers and thus decreased the CP for diapause induction and diapause intensity. It is likely that such a change occurred rapidly. My results suggest that even in $P$. zelicaon populations presumably selected for multivoltinism under natural conditions, sufficient genetic variance remains for substantial further change in the diapause characteristics. Such changes have already occurred in southern California where multivoltine populations have a greater proportion of continuous developers under long-day conditions and, in some locations with Foeniculum or Citrus, development occurs throughout the year (Emmel and Emmel, 1973; Horton, 1922; Oliver, 1969).

The numbers of matings, total pupae, and percentage diapause among broods are summarized in Table 1 . There is evidence for genetic incompatibility between the $U$ and $M$ populations since $\frac{6}{15}(40 \cdot 0$ per cent $)$ of hybrid 
crosses studied had significantly male-biased sex ratios (expected 1:1) compared to only $\frac{1}{14}(7 \cdot 1$ per cent $)$ of $M$ broods $\left(\chi^{2}=4 \cdot 26, p<0 \cdot 05\right)$ and $\frac{4}{32}(12.5$ per cent $)$ of $S$ broods $\left(\chi^{2}=4.61, p<0.05\right)$. Male-biased sex ratio distortion is often seen in crosses between species in which the female is the heterogametic sex (Haldane, 1922; Robinson, 1971). U and M populations have not yet achieved separate taxonomic status in California, and although a univoltine population of $P$. zelicaon in Colorado has been named $P$. gothica (Remington, 1968), there is considerable doubt regarding its specific status (Clarke and Sheppard, 1970; Fisher, 1977; Shapiro, 1975).

An ANOVA on the transformed percentage of diapause among matings showed that all differences between reciprocal hybrids and parental lines in the $U$ and $S$ crosses were significant (Duncan's multiple range test, $p<0.05$; table 1). Similar trends were obtained in the $\mathrm{M}$ and $\mathrm{S}$ crosses,

TABLE 1

Percent pupal diapause observed in crosses of $\mathrm{P}$. zelicaon reared at $L D 14: 10,23.5^{\circ} \mathrm{C}$

\begin{tabular}{cccc}
\hline Strain or cross & Number matings & Total pupae & $\begin{array}{c}\text { Per cent diapause among } \\
\text { matings (mean } \pm 1 \mathrm{SE})^{*}\end{array}$ \\
\hline $\mathrm{U} \times \mathrm{U}$ & 7 & 192 & $78 \cdot 7 \pm 6 \cdot 1 \mathrm{a}$ \\
$\mathrm{U} \times \mathrm{S}$ & 7 & 354 & $41 \cdot 7 \pm 8 \cdot 1 \mathrm{~b}$ \\
$\mathrm{~S} \times \mathrm{U}$ & 16 & 483 & $22 \cdot 3 \pm 4 \cdot 8 \mathrm{c}$ \\
$\mathrm{S} \times \mathrm{S}$ & 13 & 165 & $2 \cdot 8 \pm 1.5 \mathrm{~d}$ \\
& & & \\
$\mathbf{M} \times \mathbf{M}$ & 18 & 536 & $24.2 \pm 5 \cdot 7 \mathrm{a}$ \\
$\mathbf{M} \times \mathbf{S}$ & 3 & 98 & $17 \cdot 0 \pm 15 \cdot 5 \mathrm{ab}$ \\
$\mathbf{S} \times \mathbf{M}$ & 5 & 147 & $6.4 \pm 3 \cdot 9 \mathrm{~b}$ \\
$\mathbf{S} \times \mathbf{S}+$ & 13 & 165 & $2 \cdot 8 \pm 1 \cdot 5 \mathrm{~b}$ \\
\hline
\end{tabular}

* Means followed by the same letter, within a set of crosses, are not significantly different (Duncan's Multiple Range Test, $p<0.05$ ).

$\dagger$ Repeated value for statistical comparison.

but only $\mathbf{S} \times \mathbf{M}$ differed from the $\mathbf{M} \times \mathbf{M}$ value. Hybrids had an intermediate response, indicating that diapause induction is influenced by both parents, and tended to resemble the population response of the female parent. These findings are unusual for a lepidopteran. Although most previous studies of lepidopteran diapause show intermediate hybrid values suggesting polygenic inheritance, differences in reciprocal hybrid response of other species typically indicate male sex-linkage rather than maternal effects (King, 1974; Lynch and Hoy, 1978; Raina et. al., 1981; Reed et. al., 1981). A maternal influence on diapause in $P$. zelicaon has been observed in the increased diapause among progeny from previously diapausing females (Sims, 1980).

The per cent adult emergence from $U \times U, S \times S$, and hybrids is shown in table 2. For each strain and cross, the two termination conditions produced similar rates of emergence. The necessity of determining percent emergence of $U \times S$ and $S \times U$ over two different years introduced no obvious bias in the comparison. The values were therefore combined and $\chi^{2}$ analysis was performed. The reciprocal crosses were similar $\left(\chi_{1}^{2}=\right.$ $0.735, p=0.40)$, and were intermediate between and significantly different from either parent strain $\left(\chi_{1}^{2}, p=0.01\right)$. Unlike induction, an equal genetic contribution to diapause intensity was made by each parent. 
TABLE 2

Percent emergence of adult P. zelicaon in crosses exposed to laboratory and outdoor winter chilling conditions. Number in parenthesis is sample size

\begin{tabular}{lcccc}
\hline & \multicolumn{4}{c}{ Strain or cross $(\$ \times ð)$} \\
\cline { 2 - 5 } \multicolumn{1}{c}{ Diapause termination conditions } & $\mathrm{U} \times \mathrm{U}$ & $\mathrm{U} \times \mathrm{S}$ & $\mathrm{S} \times \mathrm{U}$ & $\mathrm{S} \times \mathrm{S}$ \\
\hline $11^{\circ} \mathrm{C}, \mathrm{LD} 0: 24,126$ days & 42.9 & 83.0 & 88.9 & $100 \cdot 0$ \\
& $(14)$ & $(53)$ & $(27)$ & $(57)$ \\
Outdoors Oct-June* & 53.9 & 85.2 & 90.0 & 100.0 \\
Davis, Yolo Co., Ca & $(13)$ & $(54)$ & $(20)$ & $(19)$ \\
\hline
\end{tabular}

* U X S Oct-June 1976-77; S X U Oct-June 1977-78.

Acknowledgment. Dr Arthur M. Shapiro provided material and intellectual assistance during all phases of this study. C. F. Satterwhite and C. Ainsworth aided in manuscript preparation.

\section{REFERENCES}

ClARKE, C. A. AND ShEPPARD, P. M. 1956. Hand pairing of butterfilies. Lepid. News, 10, 47-53.

ClARKe, C. A. AND ShEPPARD, P. M. 1970. Is Papilio gothica (Papilionidae) a good species? J. Lepid. Soc., 24, 229-233.

CoOlidge, K. R. 1910. A California orange dog. Pomona Coll. J. Entomol., 2, 333-334.

DETHIER, V. G. 1941. Chemical factors determining the choice of food plants by Papilio larvae. Amer. Nat., 75, 61-73.

EMMEL, T. C. AND EMMEL, J. F. 1973. The butterfies of southern California. Los Angeles County Mus. Nat. Hist. Sci. Ser., 26, 1-148.

EMMEL, J. F. AND SHIELDS, O. 1978(79). Larval foodplant records for Papilio zelicaon in the western United States. J. Res. Lepid., 17, 56-67.

FISHER, M. S. 1977. The taxonomy and identity of Papilio nitra W. H. Edwards in Colorado (Papilionidae). Bull. Allyn Mus., 47, 1-8.

HALDANE, J. B. S. 1922. Sex ratio and unisexual sterility in hybrid animals. J. Genet., 12, 101-109.

HORTON, J. R. 1922. A swallowtail butterfiy injurious to California orange trees. Mon. Bull. Calif. State Hortic. Comm., 11, 377-387.

HOY, M. A. 1978. Variability in diapause attributes of insects and mites: some evolutionary and practical implications. In Dingle, H. (ed.) Evolution of Insect Migration and Diapause, Springer-Verlag, New York, pp. 101-126.

KING, A. B. S. 1974. Photoperiodic induction and inheritance of diapause in Pionea forficalis (Lepidoptera; Pyralidae). Entomol. Exp. Appl., 17, 397-409.

LYNCH, C. B. AND HOY, M. A. 1978. Diapause in the gypsy moth: environment-specific mode of inheritance. Genet. Res. Camb., 32, 129-133.

MOSTELLER, F. AND YOUTZ, C. 1961. Tables of the Freeman-Tukey transformations for the binomial and Poisson distributions. Biometrika, 48, 433-440.

OLIVER, C. G. 1969. Experiments on the diapause dynamics of Papilio polyxenes. J. Insect Physiol. 15, 1579-1589.

RAINA, A. K., BELL, R. A. AND KLASSEN, W. 1981. Diapause in the pink bollwormpreliminary genetic analysis. Insect Sci. Appl., 1, 231-236.

REED, G. L., GUTHRIE, W. D., SHOWERS, W. B., BARRY, B. D. AND COX, D. F. 1981. Sex-linked inheritance of diapause in the European corn borer: its significance to diapause physiology and environmental response of the insect. Ann. Entomol. Soc. Amer., 74, 1-8.

REMington, C. L. 1968. A new sibling Papilio from the Rocky Mountains, with genetic and biological notes (Insecta, Lepidoptera). Postilla, 119, 1-40.

ROBINSON, R. 1971. Lepidoptera Genetics. Pergamon Press, New York.

SHAPIRO, A. M. 1975. Papilio "gothica" and the phenotypic plasticity of P. zelicaon. J. Lepid. Soc., 29, 79-84. 
SHAPIRO, A. M. AND MASUDA. K. K. 1980. The opportunistic origin of a new citrus pest. Calif. Agr., 34, 4-5.

SIMS, S. R. 1980. Diapause dynamics and host-plant suitability of Papilio zelicaon (Lepidoptera: Papilionidae). Amer. Midl. Nat., 103, 375-84.

SIMS, S. R. 1983. Prolonged diapause and pupal survival of Papilio zelicaon Lucas (Lepidoptera: Papilionidae). J. Lepid. Soc. (In press).

SOKAL, R. R. AND ROHLF, F. J. 1969. Biometry. W. H. Freeman \& Co., San Francisco.

TAUBER, C. A. AND TAUBER, M. J. 1981. Insect seasonal cycles: genetics and evolution. Annu. Rev. Ecol. Syst., 12, 281-308. 